Int. J. Odontostomat., 6(1):19-26, 2012.

\title{
Use of Homologous Bone Grafts in Maxillary Sinus Lifting
}

\author{
Uso de Injertos de Hueso Homólogo en la Elevación del Seno Maxilar
}

\begin{abstract}
Ana Cláudia Rossiं; Alexandre Rodrigues Freire*; Mário Roberto Perussi*; Paulo Henrique Ferreira Caria* \& Felippe Bevilacqua Prado*
\end{abstract}

ROSSI, A. C.; FREIRE, A. R.; PERUSSI, M. R.; CARIA, P. H. F. \& PRADO, F. B. Use of homologous bone grafts in maxillary sinus lifting. Int. J. Odontostomat., 6(1):19-26, 2012.

\begin{abstract}
Homologous bone has been considered a viable alternative in bone reconstruction in the posterior maxillary area to perform surgeries for the maxillary sinus lifting. The aim of this study was to perform a literature review about the advantages and risks inherent in the use of homologous bone graft coming from the tissue bank to perform the surgery for maxillary sinus lifting. A literature review was conducted on MEDLINE (PubMed), Scielo, Scopus and Lilacs, and based on manuscripts and books published from 1980 to 2010. After reading the titles and abstracts of the manuscripts, 69 studies were selected because of their correlations with the aim of the current study. The use of homologous grafts from bone banks showed greater osteogenic potential and a slow remodeling least compared to other grafts to increase the volume of the posterior bone of the maxilla in surgery for maxillary sinus lifting.
\end{abstract}

KEY WORDS: Extra-oral donor site, homologous bone, maxillary sinus lift.

\section{INTRODUCTION}

The maxillary bone atrophy is usually caused by loss of teeth, infections, trauma, tumor resections and/ or developmental abnormalities. Such lesions, besides not repairing themselves spontaneously, are enhanced by the absence of stimuli, affecting the form and function of the skull (Fontana et al., 2008). The loss of teeth causes the narrowing of alveolar bone crest width, loss of height and reduction of cancellous bone. Thus, stimuli that maintain the morphology of the alveolar bone are lost with the teeth absence (Chanavaz, 1990).

Bone resorption in maxillary alveolar process at posterior region may limit the implant installation with adequate length to achieve stability under masticatory loads (Taga, 1996). Thus, the repair of the resorbed alveolar bone is one of the current challenges of dental clinics, whose the search to appropriate height and width are necessary to accommodate the appropriate implant dimensions, with an axial angle that allows the placing of the prosthesis (Costa \& Trevisan Júnior, 2007).

The main indication for maxillary sinus lifting refers to creating better conditions for installation of implants at the maxillary posterior region that presents insufficient bone volume and subsequent pneumatization of the maxillary sinus (Taga).

The grafts, as to their source, may be: autogenous, when obtained from the same individual, being the receiver and donor; isogeneous, when obtained from another individual with the same genetic; homologous, when obtained from different individuals with different genetic, but the same species; heterogeneous, which are obtained from other species (Rodriguez et al., 2003).

The use of homologous bone (human bone, fresh and frozen) has proven to be effective in many situations where grafting for bone repair in implant dentistry is considered extensive, especially for maxillary sinus lifting (Albert et al., 2006).

Thus, the aim of this study was to review the literature on the advantages and risks inherent to use of homologous bone graft from tissue bank for maxillary sinus lifting. 


\section{MATERIAL AND METHOD}

A literature review was searched on databases: MEDLINE (PubMed) SciELO, Scopus and Lilacs. The keywords used were: extra-oral donor site, homologous bone, maxillary sinus and lift. The manuscripts and books published were published from 1980 to 2010. After reading the titles and abstracts of the manuscripts, 69 studies were selected because of their correlations with the aim of the current study.

\section{LITERATURE REVIEW}

Bone grafts in Dentistry. The repair of bone defects represents a challenge for dentistry, as many injuries produce sequel with functional or aesthetic impairment and reduces life quality of the individual affected. Thus, the use of bone grafts is a feasible alternative to repair of the lost bone tissue (Von Arx \& Cochran, 2003).

Bone is the most remodeling tissue due to its vascularization and dynamics, which changes throughout the life of the individual (Desai, 2007). When injured, has an ability to repair without the presence of scars, but in some situations due to the size of the defect, the bone does not completely repair (Masters, 1988).

Extraction is the most common trauma that results in alveolar bone loss due to atrophy of edentulous alveolar process. In many circumstances, this is a limiting factor to rehabilitation with dental implants, due to insufficient bone volume, may be indicated the use of grafts (Pappalardo et al., 2007).

The gold standard of grafting is autogenous bone, particularly bone marrow, due to their biological properties and the absence of rejection (Virolainen et al., 2003). According to Jensen et al. (1990), the autogenous bone was more effective in the process of bone formation when compared with tricalcium-beta phosphate and inorganic bovine bone through histological and histomorphometric analysis in pigs. This fact adds to the already established assertion that the best material is autogenous bone grafting. However, it is not always effective to use for different variables, such as the extensive defect areas (Jensen et al., 2006).

The autogenous bone requires the need of additional surgery to remove the material, creating a wound which can be uncomfortable to the patient than surgery intervention to correct the deformity (Ellis \& Sinn, 1993). The need of bloody procedure on the donor area at the moment of use of autogenous bone leads to an increase in the recovery period (Feitosa et al., 2007), susceptibility to infections (Del Valle et al., 2007), risk of progressive bone resorption and morbidity (Hallman \& Nordin, 2004). These difficulties have stimulated the search for other graft materials to be used as a substitute for autogenous bone graft.

The heterogeneous and homologous bone grafts, and synthetic bone substitutes have been widely studied as an alternative to autogenous grafts. Thus, the homologous bone (human bone, fresh and frozen), mainly taken from the tibia, fibula, calvaria and iliac crest, is a viable alternative in reconstruction of atrophic maxillary bone (Fontana et al.).

The bone graft materials can be classified as osteogenic, osteoinductive and osteoconductive. The osteogenic are organic materials to able of stimulating the bone formation directly from osteoblasts. The osteoinductive are capable of inducing the differentiation from mesenchymal cells into osteoblasts or chondroblasts, increasing the bone formation at the site or even stimulating the bone formation at heterotopic site (Wannfors et al., 2000). Osteoconductive materials (usually inorganic) allow the new bone apposition on its surface, requiring the presence of pre-existing bone tissue as a source of osteoprogenitor cells (Mozella et al., 2005).

Homologous bone does not contain live cells, but may have osteoinductive or osteoconductive characteristics in their integration to the receptor sites. These grafts do not need a second surgical site (donor) and thus has less time to perform reconstructive surgery (Feofiloff \& Jesus-Garcia, 1996). This type of graft acts as a scaffold to support the new bone formation, with similar characteristics to autogenous bone, although it is slower for revascularization and osseointegration (Carvalho et al., 2004).

Maxillary sinus lifting. Maxillary sinus is a large cavity in the body of maxilla. Its growth in the vertical direction is conditioned by the eruption of the teeth, while in the antero-posterior direction depends on the development of the maxillary tuberosity (Costa \& Trevisan Júnior).

The size of the maxillary sinus can range from $3 \mathrm{cc}$ to $12 \mathrm{cc}$. Changes in volume may occur in one person, ranging from side to side, or may be congenital 
or acquired causes. These variations also occur due to premature tooth extraction resulting in magnifying of the effect of internal pressure in the sinus, generating bone resorption (Chanavaz).

The alveolar process of the maxilla at the posterior region approaches topographically to maxillary sinus due to teeth loss, leading to resorption of alveolar bone (Chanavaz). Thus, after teeth loss, the periosteum of the sinus membrane has an intense osteoclastic activity resulting in resorption of the sinus floor. The posterior maxillary alveolar process follows a centripetal resorption with gradual bone loss from buccal plate to the palate. In addition, increased internal pressure can generate a pneumatization of the maxillary sinus (Lyford et al., 2003).

The progressive dental loss may interfere in the shape and volume of the maxillary sinuses, which tends to occupy the alveolar spaces that were occupied by the teeth. Genetic factors and factors related to individual bone structure predispose different degrees of bony resistance and resorption (Hallman \& Nordin).

The posterior region of the maxilla is a difficult area for installation and maintenance of implants (Chanavaz). Thus, the use of dental implants in this region is a challenge in fixed implant-supported rehabilitation due to pneumatization of the maxillary sinus, inadequate morphology of alveolar bone crest and poor bony quality (Haas et al., 2003).

Maxillary sinus lifting has become an alternative for patients with moderate to severe alveolar resorption and pneumatization of the maxillary sinus (Chiapasco \& Ronchi, 1994; Contar et al., 2009; Costa \& Trevisan Júnior; Fontana et al.; Toledo Filho et al., 2001). Thus, the main indication for raising of sinus floor refers to creating better conditions for the installation of implants in the maxillary posterior regions that have insufficient bone width, i.e., less than $8 \mathrm{~mm}$ in height and $4 \mathrm{~mm}$ (Jensen et al., 1990). The appropriate amount of bone to be regenerated allows the optimally placement of implants, with a minimum height of $10 \mathrm{~mm}$ and a width of $4.8 \mathrm{~mm}$ or larger in the posterior maxilla (Del Valle et al.).

The success of the implant depends on the interface, obtained from the biomaterial to be used as a graft, and bone (Abrahams et al., 2000). Such interface should allow effective transmission and homeostatic occlusal forces. The rehabilitation of edentulous in the posterior maxilla by applying of procedures for lifting the maxillary sinus has become a routine procedure in contemporary implant dentistry, being safe and with satisfactory results (Imamaliev et al., 1984).

The procedure for maxillary sinus lifting has been described, also, a two stages procedure with a healing phase of 4 to 6 months to allow integration of biological graft (Lyford et al.). To treat these patients, two surgical techniques were developed. In the procedure at the same time or at one stage, the implants are placed in the same moment of sinus lifting through grafts. In two stages procedure, the graft is placed first and, after the maturation phase, the implants are installed (Tecimer \& Behr, 2001). Depending on the amount of remaining alveolar bone, implants can be placed or not with bone graft simultaneously (Toledo Filho et al.).

Advantages of the one stage procedure with the installation of implant at the same sinus lifting surgery consist in reducing the healing time and less risk of resorption of the grafted bone (Chiapasco \& Ronchi).

There are several advantages to delay the installation of implant during four months, such as: the individual healing rate of the graft can be evaluated, while the implant osteotomy is being prepared; bone requires to form blood vessels and subsequently remodeling. An implant placed immediately after grafting could lead to a poor vascular supply, the increase in bone width can be indicated with the sinus graft to restore maxillo-mandibular relations and bone width for future implant placement; sinus bone graft is denser with delayed insertion of the implant and, as well, the angle and positioning of the implant will be satisfactory (Costa \& Trevisan Júnior).

Wannfors et al. installed 76 implants in procedures in one stage, and 74 implants in the procedure in two stages. After one year, 20 implants were lost in the one stage and 11 implants were lost in the two stage procedure. These authors concluded that the risk of the procedure in one stage is about two times the risk in cases performed in two surgical stages.

The most common complication during maxillary sinus lifting is the sinus membrane perforation, occurring in about 10 to $40 \%$ of cases. Other complications can occur such as infection of the maxillary sinus, with or without implant loss, oral antral fistula formation or communication, bleeding, opening of the incision line and chronic sinusitis in the postoperative period (Del Valle et al.).

Homologous bone graft from tissue banks for use in maxillary sinus lifting. The ideal graft characteristics include a non limited source, no donor site morbidity, 
universal donor material, no risk of disease transmission, high in promoting bone healing, provide immediate stability, multiple ways for versatility, excellent handling properties, adequate life and affordable cost (Aalam \& Nowazari, 2007; Figueiredo et al., 2008).

As alternative for autogenous bone grafts, homologous bone grafts have been used and presents as major advantage the bone tissue removal in unlimited quantity (Tecimer \& Behr).

In homologous bone graft, the tissue comes from deceased donors or living donors who lose a limb from amputation. The best donor sites are the tibia and femur, as these have thick and bulky cortical, which facilitate bone regeneration (Eppley et al., 2005).

Homologous bone grafts may be indicated for arthroplasty, surgical reconstruction, major bony changes by tumor surgery or trauma, as well as are also used in neurosurgery, and reconstruction in maxillofacial surgery (Chiapasco \& Ronchi).

There are several kinds of homogenous graft, including dust, cortical plates, spongial bone cubes, particles, among others. Many of these could not be collected the required amount from the donor, since they could have injury of donor site (Figueiredo et al.).

The homologous bone is primarily osteoconductive, although there may be some osteoinductive capacity, depending on the manner in which it is processed. In most cases, this type of bone graft does not have osteogenic potential, because there is no living cells present in the processed bone tissue and, therefore, cannot request an osteogenic response (Urist, 1980).

This bone graft presents complications, such as the possibility of transmitting infectious diseases, to cause immune reactions, having less repair process ability, slowly consolidation and increase the risk of postoperative infections. Among infectious diseases, the predominant are the human immunodeficiency syndrome, hepatitis, fungal bone infections and bacterial infection such as syphilis (De Riu et al., 2007). In order to reduce the risk of cross contamination, tissue banks have been created and developed sterilization procedures for added security of homologous grafts (Ludwig et al., 2000).

Gutierrez et al. (2006) reported that the available unlimited amount is an advantage of homogeneous graft compared to autogenous, as well as the dispensability of an additional surgery in the patient, for its collection.

Gondak et al. (2007) concluded that the availability of homologous bone increased the agility in performance of treatment techniques and facilitated the emergence of innovative ways to reach many reconstructive challenges.

Tanaka et al. (2008) reported that the homologous bone is considered the first choice, it does not require the donor site, can provide significant amounts of material, different combinations of bone (cortical, cancellous or cortical-cancellous), be processed (demineralized, lyophilized and fresh), precast (ensuring best fit in the receptor site and less surgical time) and is considered osteoconductive.

Rondinelli et al. (1994) reported that comparing the autogenous graft, the homologous graft presents the ability to slower bypass and the union between the graft and recipient site is obtained in a non-uniform condition.

Baptista et al. (2003) highlighted that one of the disadvantages of homologous grafts involve the risk of disease transmission and the potential antigenicity. These complications can be controlled by freezing and storage methods. The risk of infection can be reduced through serological testing in the donors, discard of material which produces a positive bacterial culture, graft manipulation under aseptic conditions and sterilization, whether by radiation or ethylene oxide.

Del Valle et al. reported that homologous bone graft presents major resorption through remodeling of the block, being greater when compared with autogenous bone, indicating that should use larger and thicker fragments to compensate for the resorption effects, affecting the aesthetics and increasing the risk of suture dehiscence.

The donors are subjected to the rules of the American Association of Tissue Bank (AATB). Diseases such as AIDS, hepatitis, syphilis, tuberculosis, fungal infections or metastatic disease exclude potential donors. As well as patients are excluded when presenting evidence of systemic or localized disease in the bones and soft tissues, victims of death by poisoning, major burns, patients who had remained with assisted breathing for more than 72 hours or patients who ingested drugs or toxic substances. Usually, 
patients who suffered brain death due to gunshot injury, stroke or acute myocardial infarction, or multiple organ donors and living amputees with prior authorization. The bones most commonly used are: humerus, radius, ulna, femur, tibia and fibula (Aho et al., 1998).

Mozella et al. determined that the capture is performed in a period up to 12 hours after cardiopulmonary arrest or within 24 hours if the corpse was cooled at the first 6 hours.

The fragment removal should be initiated at the limbs and, finally, at the hip, as a region with more possibility to contamination. After collection, the graft is prepared, where the soft tissue and cartilage are removed. Subsequently, the fragments should be washed in antibiotic solution, removed small pieces and placed in containers with double protection for a culture (Amatuzzi et al., 2000). The piece is packed in casings, with antibiotic solution, such as vancomycin and gentamicin, hermetically sealed and sent, under refrigeration at a temperature of $-4^{\circ} \mathrm{C}$, to the tissue bank for immediate processing (Virolainen et al.).

The grafts are stored at temperatures below $70^{\circ} \mathrm{C}$, in containers, temporarily separated until the results of laboratory tests. If there is any detection of disease or infection that developed in the living donor, the graft should be discarded or, if there is clearance for use of graft, it can be stored for up to 5 years. In all grafts, radiographs are performed in order to detect preexisting lesions or malformations that may damage the receiver (Virolainen et al.).

Homologous grafts must undergo processing with the aim of sterilization and reduction of antigenicity, but with maintenance of their biological characteristics. For processing, acids, such as hydrochloric acid associated with a solution composed of $5 \%$ calcium, pumping in water for 12 hours, freeze drying, and storage at $-80{ }^{\circ} \mathrm{C}$ can be used. This step ensures sterilization and preservation of osteoconductive and osteoinductive properties. However, the careful donor selection is critical in preventing transmission of infectious diseases (Amatuzzi et al.).

Cruz et al. (2005) reported that homologous grafts are shaped as decalcified, freeze and dried human bone (DFDBA) and mineralized, freeze and dried human bone (FDBA). These materials act by different mechanisms. While the FDBA presents osteoconductive property, the DFDBA has osteoinductive.
Lyford et al. reported that the main indication of homologous bone is the absence of autogenous bone. In the indications is also include the fact that the patient presents, in some cases, resistance against the need to a second surgical site. This activity is often associated with problems at the postoperative phase, such as suture dehiscence, pain and infection.

Gutierrez et al. classified the homogenous bone graft bone as a bone from a donor of same species. Currently, it is not used without prior preparation (fresh), due to the inflammatory response and risks of disease transmission.

Potential bone donors are individuals with brain death, after the family consent, or healthy patients undergoing elective surgery, such as requiring removal of bone fragments (hip arthroplasty), which also allow the donation of their bones. These bone fragments can results in health risks for the receiver, such as disease transmission, immune reactions and infections. Thus, in order to reduce these risks, hospitals created banks of musculoskeletal tissues. These banks aimed for collecting, processing, storage and selection, where the homologous grafts can be used with minimum risks (Wallace \& Froum, 2003).

The use of homologous bone in maxillofacial surgery has resulted in a faster and less traumatic surgery than when using autogenous bone, as the need for surgical access to remove the bone from a donor area became unnecessary (Roos et al., 2000).

Gomes et al. (2008) used three different grafting techniques (onlay block, onlay block associated to particulate bone in maxillary sinus and only particulate bone in the maxillary sinus). The results showed that after 8 months with the installation of the implants, the homologous bone can be considered a useful alternative when compared with the use of autogenous bone. Because of ease of handling, there is a large amount of graft available and the possibility of using local anesthesia and, consequently, a reduction of patient morbidity.

Paraendodontic surgery, periodontal regeneration, orthognathic surgery, maxillary sinus lift and reconstruction of atrophic alveolar ridge represent some of the indications for the use of homologous bone graft in dentistry. Levandowsky et al. (2008) reported that despite the security provided by autogenous bone for repair of alveolar defects, is constant to search for alternatives that eliminate or reduce the morbidity of a 
second surgical area. The reconstruction of alveolar defects with bone blocks is common and essential for the placement of implants in an ideal position, with subsequent proper prosthetic restoration. Although there are studies related to homologous bone block in Orthopedics and Medical Traumatology, few cases have been reported including dental alveolar ridges reconstructions, while the bone grafts for homologous block is used to correct deformities and maxillary sinus lifting (Dalapicula et al., 2006).

Costa \& Trevisan Júnior reported a case in which homologous bone graft was used, from the bone bank of the Clinics Hospital of Curitiba, showing the use of this type of bone graft as an alternative in cases of atrophy at the posterior region of maxilla. After surgery, biopsies were performed, in which was proved the osteogenesis at the receiving area of homologous graft.

According to Figueiredo et al., the use of homologous bone graft, from a bone bank, prior to implant placement in the posterior region of the maxilla, represents a viable alternative to increasing the bony ridge volume. Homologous bone grafts, after histopathologic study, proved to be biocompatible, with successfully repairing and absence of immune response.

Contar et al. demonstrated that the fresh frozen bone can be a useful material as graft for treatment of defects and maxillary sinus lifting, as the appropriate surgical techniques allows the use of this bone safely, being an appropriate alternative for autogenous bone grafts.

In conclusion, the studies have shown that the use of homologous grafts from bone banks demonstrated major osteogenic potential and slow remodeling compared to other grafts to increase the bone volume at the posterior region of maxilla in maxillary sinus lifting.

Thus, despite the advantages offered by autogenous graft, particularly regarding to their biological properties for osteogenesis, osteoinduction and osteoconduction, the homologous grafts can be considered as an effective and safe alternative in cases of maxillary sinus lifting. This therapy was satisfactory, as presented little clinical operatory time, less discomfort to patients and enough amount of bone, regardless the extent of receiving area.

ROSSI, A. C.; FREIRE, A. R.; PERUSSI, M. R.; CARIA, P. H. F. \& PRADO, F. B. Uso de injertos de hueso homólogo en la elevación del seno maxilar. Int. J. Odontostomat., 6(1):19-26, 2012.

RESUMEN: De hueso homólogo se ha considerado una alternativa viable en la reconstrucción ósea en la zona posterior del maxilar para cirugías de la elevación del seno maxilar. El objetivo de este estudio fue el desempeño de una revisión de la literatura sobre las ventajas y riesgos inherentes en el uso de injerto de hueso homólogo proveniente del banco de tejidos para la cirugía de elevación del seno maxilar. Una revisión de la literatura se hizo en MEDLINE (PubMed), Scielo, Scopus y Lilacs, y en base a manuscritos y libros publicados desde 1980 hasta 2010. Después de leer los títulos y resúmenes de los manuscritos, 69 estudios fueron seleccionados debido a su correlación con el objetivo de este estudio. El uso de injertos homólogos de los bancos de hueso mostró un mayor potencial osteogénico y una remodelación lento por lo menos en comparación con otros injertos para aumentar el volumen del hueso posterior del maxilar superior en la cirugía de elevación del seno maxilar.

PALABRAS CLAVE: Zona donante extra-oral, hueso homólogo, elevación de seno maxilar.

\section{REFERENCES}

Aalam, A. A. \& Nowzari, H. Mandibular cortical bone grafts part 1: anatomy, healing process, and influencing factors. Compend. Contin. Educ. Dent., 28(4):206-12, 2007.

Abrahams, J. J.; Hayt, M. W. \& Rock, R. Sinus lift procedure of the maxilla in patients with inadequate bone for dental implants: radiographic appearance. Am. J. Roentgenol., 174(5):1289-92, 2000.

Aho, A. J.; Hirn, M.; Aro, H. T.; Heikkilä, J. T. \& Meurman O.
Bone bank service in Finland. Experience of bacteriologic, serologic and clinical results of the Turku Bone Bank 1972-95. Act. Orthop. Scand., 69(6):559-65, 1998.

Albert, A.; Leemrijse, T.; Druez, V.; Delloye, C. \& Cornu, O. Are bone autografts still necessary in 2006? A three-year retrospective study of bone grafting. Acta Orthop. Belg., 72(6):734-40, 2006.

Amatuzzi, M. M.; Croci, A. T.; Giovani, A. M. M. \& Santos, L. 
A. U. Tissue bank: structure and organization. Rev. Bras. Ortop., 35(5):65-72, 2000.

Baptista, A. D.; Sorrilha, A.; Tormes, T. A. M.; Abdoune, Y. A.; Croci, A. T.; Camargo, O. P. \& Oliveira C. R. G. C. M. A histological study of human allografts. Act. Ort. Bras., 11(4):220-4, 2003.

Carvalho, P. S. P.; Bassi, A. P. F. \& Pereira, L. A. V. D. Revision and nomenclature proposal for the biomaterials. ImplantNews, 1(3):255-60, 2004.

Chanavaz, M. Maxillary sinus: anatomy, physiology, surgery, and bone grafting related to implantology: eleven years of surgical experience (1979- 1990). J. Oral Implantol., 16(3):199-209, 1990.

Chiapasco, M. \& Ronchi, P. Sinus lift and endosseous implants-preliminary surgical and prosthetic results. Eur. J. Prosthodont. Rest. Dent., 3(1):15-20, 1994.

Contar, C. M.; Sarot, J. R.; Bordini Jr, J.; Galvão, G. H.; Nicolau, G. V. \& Machado, M. A. Maxillary ridge augmentation with fresh-frozen bone allografts. J. Oral Maxillofac. Surg., 67(6):1280-5, 2009.

Costa, R. R. \& Trevisan Júnior, W. Elevation of bilateral maxillary sinus with the use of homogenous bone from a bone bank: a feasible alternative. ImplantNews, 4(5):51320, 2007.

Cruz, G. A.; Sallum, E. A. \& Toledo, S. Morphological study of bone substitutes by using scanning electron microscopy. Periodontia, 15(3):21-8, 2005.

Dalapicula, S. S.; Vidigal Junior, G. M.; Conz, M. B. \& Cardoso, E. S. Characteristics physicochemical of the biomaterials used of bone grafts. A critical review. Implant News, 3(5):487-91, 2006.

De Riu, G.; De Riu, N.; Spano, G.; Pizzigallo, A.; Petrone, G. \& Tullio, A. Histology and stability study of cortical bone graft influence on titanium implants. Oral Surg. Oral Med. Oral Pathol. Oral Radiol. Endod., 103(4):1-7, 2007.

Del Valle, R. A.; Carvalho, M. L. \& Gonzalez, M. R. Study of bone graft behavior with bank donator material of muscleskeletal tissues. Rev. Odontol. Univ. Cid. São Paulo, 18(2):189-94, 2006.

Desai, B. M. Osteobiologics. Am. J. Orthop., 36(4): 8-11, 2007.

Ellis, E. \& Sinn, D. P. Use of homologous bone in maxillofacial surgery. J. Oral Maxillofac. Surg., 51(11): 1181-93, 1993.

Eppley, B. L.; Pietrzak, W. S. \& Blanton, M. W. Allograft and alloplastic bone substitutes: a review of science and technology for the craniomaxillofacial surgeon. $J$. Craniofac. Surg., 16(6):981-9, 2005.
Feitosa, A. S.; Monteiro, A. S. F.; Santos, C. A.; Macedo, N. L. \& Macedo, L. G. S. Osso humano fresco congelado em reconstruções ósseas: estudo retrospectivo e relato de casos. Braz Oral Res., Suppl.(1):159, 2007.

Feofiloff, E. T. \& Jesus-Garcia, R. Banking methods for bone allografts: Protocol of the Bone Bank of Escola Paulista de Medicina. Rev. Bras. Ortop., 31(11):895-903, 1996.

Figueiredo, M. N.; Bastos, A. S.; Spin Neto, R.; Marcantonio Junior, E. \& Marcantonio, E. Allogeneic bone graft as an alternative for atrophic maxillary anterior region augmentation: case report. Implant News, 5(3):269-74, 2008.

Fontana, F.; Santoro, F.; Maiorana, C.; lezzi, G.; Piattelli, A. \& Simion, M. Clinical and histologic evaluation of allogeneic bone matrix versus autogenous bone chips associated with titanium reinforced e-PTFE membrane for vertical ridge augmentation: a prospective pilot study. Int. J. Oral Maxillofac. Implants. 23(6):1003-12, 2008.

Gomes, K. U.; Carlini, J. L.; Biron, C.; Rapoport, A. \& Dedivitis, R. A. Use of allogeneic bone graft in maxillary reconstruction for installation of dental implants. J. Oral Maxillofac. Surg., 66(11):2335-8, 2008.

Gondak R, Duvoisin, C.; Drechsel, L. \& Navarro Junior, W. Musculoskeletal tissue bank: collects, processing and distribution. Implant News, 4(6):665-9, 2007.

Gutierres, M.; Lopes, M. A.; Hussain, N. S.; Cabral, A. T.; Almeida, L. \& Santos, J. D. Substitutos Ósseos: conceitos gerais e estado actual. Arq. Med., 19(4):153-62, 2006.

Haas, R.; Watzak, G.; Baron, M.; Tepper, G.; Mailath, G. \& Watzek, G. A preliminary study of monocortical bone grafts for oroantral fistula closure. Oral Surg. Oral Med. Oral Pathol. Oral Radiol. Endod., 96(3):263-6, 2003.

Hallman, M. \& Nordin, T. Sinus floor augmentation with bovine hydroxyapatite mixed with fibrin glue and later placement of nonsubmerged implants: A retrospective study in 50 patients. Int. J. Oral Maxillofac. Implants, 19(2):222-7, 2004.

Imamaliev, A. S.; Lirtsman, V. M. \& Babovnikov, V. G. Traffic injuries of the extremities. Khirurgiia (Mosk), 11:103-7, 1984.

Jensen, J.; Simonsen, E. K. \& Sindet-Pedersen, S. Reconstruction of the severely resorbed maxilla with bone grafting and osseointegrated implants: A prelimary report. J. Oral Maxillofac. Surg., 48(1):27-32, 1990.

Jensen, S. S.; Broggini, N.; Hjørting-Hansen, E.; Schenk, R. \& Buser, D. Bone healing and graft resorption of autograft, anorganic bovine bone and beta-tricalcium phosphate: a histologic and histomorphometric study in the mandibles of minipigs. Clin. Oral Implants Res., 17(3):237-43, 2006. 
Levandowski, J. R. N.; Pfeifer, A. B.; Paza, A. O.; Valiati, R. \& Silva, M. R. P. B. The use of allogeneic bone block for alveolar ridge augmentation: a literature review. Implant News. 5(1):51-7, 2008.

Ludwig, S. C.; Kowalski, J. M. \& Boden, S. D. Osteoinductive bone graft substitutes. Eur. Spine J., 9(1):119-25, 2000.

Lyford, R. H.; Mills, M. P.; Knapp, C. I.; Scheyer, E. T. \& Mellonig, J. T. Clinical evaluation of freeze-dried block allografts for alveolar ridge augmentation: a case series. Int. J. Periodontics Restorative Dent., 23(5):417- 25, 2003.

Masters, D. H. Implants. Bone and bone substitutes. Calif. Dent. Assoc. J., 16(1):56- 65, 1988.

Mozella, A. P.; Araújo Neto, C. A. S.; Fernandes, M. B. C. \& Regado, E. R. Análise Epidemiológica da obtenção, processamento e utilização de enxertos homólogos pelo banco de tecidos. Rev Into.,; 3(1):34-40, 2005.

Pappalardo, S.; Puzzo, S.; Carlino, V. \& Cappello, V. Bone substitutes in oral surgery. Minerva Stomatol., 56(10):54157, 2007.

Rodriguez, A.; Anastassov, G. E.; Lee, H.; Buchbinder, D. \& Wettan, H. Maxillary sinus augmentation with deproteinated bovine bone and platelet rich plasma with simultaneous insertion of endosseous implants. J. Oral Maxillofac. Surg., 61:157-63, 2003.

Rondinelli, P. C.; Cabral, F. P.; Freitas, E. H.; Penedo, J. L.; Leite, J. E. R. \& Silveira, S. L. C. Bone bank routine of the Hospital de Traumato-Otırtopedia (HTO-RJ). Rev. Bras. Ortop., 29(6):385-8, 1994.

Roos, M. V.; Camisa Jr, A. \& Michelin, A. F. Procedures of a bank bones and aplicability of the grafts offered by surch bank. Acta Ortop. Bras., 8(3):122-7, 2000.

Taga, E.M. Biomaterials in dentistry and medicine. BCl., 3(1):30-9, 1996.

Tanaka, R.; Yamazaki, J. S.; Sendyk, W. R.; Texeira, V. P. \& França, C. M. Bone block graft incorporation: biologic process and relevant considerations. ConScientiae Saúde, 7(3):323-7, 2008.

Tecimer, D.; Behr, M. M. Use of autogenous bone grafting to reconstruct a mandibular knife edge ridge before implant surgery: a case report. J. Oral Implantol., 27(2):98-102, 2001.

Toledo Filho, J. L.; Marzola, C. \& Rodriguez Sanches, M. P. The bone implants and the biomaterials and the osseointegrated implants. Rev. Bras. Cir. Implant., 8:127-43, 2001.
Urist, M. R. Bone transplants and implants. In: Fundamental and clinical bone physiology. J.B. Lippincott, Philadelphia, 1980. p.p. 331-68.

Virolainen, P.; Heikkilä, J.; Hirn, M.; Aro, H. T. \& Aho, A. J. 30 years of bone banking at Turku bone bank. Cell Tissue Bank., 4(1):43-8, 2003.

Von Arx, T. \& Cochran, D. L. Rationale for the application of the GTR principle using a barrier membrane in endodontic surgery: a proposal of classification and literature review. Int. J. Periodontics Restorative Dent., 21(2):127-39, 2001.

Wallace, S. \& Froum, S. Effect of maxillary sinus augmentation on the survival of endosseous dental implants: a systematic review. Ann. Periodontol., 8(1):328-43, 2003.

Wannfors, K.; Johansson, B.; Hallman, M. \& Strandkvist, T. A prospective randomized study of 1-and 2-stage sinus inlay bone grafts: 1-year follow-up. Int. J. Oral Maxillofac. Implants., 15 (5):625-32, 2000.

Correspondence to:

Alexandre Rodrigues Freire

Department of Morphology, Piracicaba Dental School,

State University of Campinas - UNICAMP.

Av. Limeira, 901

Postal Box \#52

zip code 13414-903,

Piracicaba

São Paulo,

BRAZIL

Phone number: 551921065200

E-mail: alefreire@fop.unicamp.br

Received: 27-11-2011

Accepted: 12-01-2012 